\title{
Visiting Mother Tree schools in India: Creating Conditions of Enablement
}

\author{
Lorayne Robertson, Dhurka Janani Srikantha \\ Ontario Tech University, Canada
}

\begin{abstract}
Most nations globally who are working to build quality educational systems are also struggling with the education of students who learn differently from the mainstream school population. Recently we visited five schools in India who have taken extraordinary steps toward building enabling environments that in-clude all students. While analyzing our conversations with these remarkable schools, we construct a meta-phor of the Mother Tree School. We cite research on mother trees indicating that trees connect to each other through fungi root connections underground. This allows trees to communicate needs to their network, and the mother trees transfer nutrients silently and unobtrusively to the trees that need it most. Remarkably, the leadership of the mother tree allows for specialized support yet also enables all of the trees to flourish. Similarly, we find that some schools in India, even prior to the Right to Education Act that came into effect in 2010, are providing unique examples of teachers and parents working within communities of practice to provide active, experiential learning expe-riences that show student-centered pedagogies. The Mother Tree schools' unique blend of pedagogy and professional development allows them to meet the needs of more students, including those with excep-tional learning profiles.
\end{abstract}

\section{Introduction}

Serving the needs of students in schools is a major challenge for every nation regardless of the level of development of the country. But serving the needs of every student, including those students who have special learning needs, increases the level of this challenge. At the same time, providing recognition and dignity in society and providing a high-quality education for the most vulnerable members of society is a high calling for the citizens of every nation. Even those countries who have recognized the rights of students with special needs with legislation and policies can struggle with providing a quality education for them. Consider these statements from a recently-published review of charter schools in California, USA [1].
Our nation's special education system has proven to be ineffective, compliance-driven, and costly. Despite decades of incremental progress, students with disabilities continue to lag far behind their peers on every measure test scores, graduation, college entrance and completion, and employment. This achievement gap is even more pronounced among historically-underserved groups. [1]

We find ourselves in an era where we have ac-cess to global education systems and can learn from other school systems through conferences, publications and many forms of digital communication. One of the ways that global school systems can distinguish themselves from each other is through their treatment of the students who learn differently from the mainstream, and who, for various reasons, are marginalized in society. Yet, as the world becomes more closely connected through ease of travel and through the affordances of the Internet, there is a growing recognition that diversity, rather than sameness, should be the expectation and the new normal [2]. Kalantzis and Cope argue persuasively that an inclusive approach to schooling that anticipates that there will be diversity in the classroom (and plans for it) is a much more effective approach to student learning; planning for diverse learners using different teaching and learning strategies deepens student engagement and improves learner performance [2].

In this paper, we report on our visits to five schools in India where the teacher educators and their school leaders are conversant about inclusion and enact a philosophy of inclusion for students of different backgrounds, skills and ability levels within the classroom. Our observations in the schools were supple-mented by dialogue with the teachers and teacher lead-ers from these same five schools. As they shared their successes and challenges with inclusive education, some common themes emerged which characterized these schools as places where children could find sup-port systems which we compare to the organic work of Mother Trees. Our findings are reported here along with some thoughts about future steps toward inclu-sion that might be considered by schools globally as they strive to meet the needs of every child. 


\section{India: Characterized by its diversity}

India has a population of approximately 1.3 bil-lion people and while it has been described as the world's largest democracy [3], it is possibly a country that is more characterized by its diversity. There are multiple forms of diversity, starting with its linguistic diversity, income levels, social hierarchies, and numerous religions. These social areas of diversity are in addition to the diverse ways that people are able or not able to participate in all aspects of life based on factors such as physical or mental capability. To help the reader grasp the extent of diversity, each of these areas of diversity are discussed next as they relate to educa-tion.

First, according to Dasgupta [4], there is significant linguistic diversity which impacts on social co-hesion in India. Earlier official studies (such as Grier-son's of 1909-1928) identified 179 languages and 544 dialects, and the 1951 census revealed 845 languages or dialects, but in general terms, $87 \%$ of the Indian population speaks one of the 14 major languages which align somewhat with the twelve districts of In-dia. These include: Assamese, Bengali, Gujarati, Hindi, Kannada, Kashmiri, Malayalam, Marathi, Ne-pali, Oriya, Punjabi, Sindhi, Tamil, Telugu, Urdu, English and Sanskrit. While Hindi was proposed as the official language because it was known by about $30 \%$ of the population, one of the major issues for social cohesion is that only a portion of the country was bilingual at that time, so language has been a barrier to communication. English is considered the mode of the communication for the official, academic and cosmo-politan aspects of Indian life [4]. According to the BBC, there are claims now that India is the second-largest English speaking country with an estimated $10 \%$ or 125 million English speakers [5]. Still, a sig-nificant portion of the country's population is neither bilingual nor English speaking, and thus there are mul-tiple ways that linguistic diversity impacts on the im-plementation and enactment of official policies.

Secondly, there is a diversity of income levels in India, as well as a social hierarchy that has longstanding elements of social privilege and exclusion. Groups of people who are considered indigenous and officially recognized in India's policies and constitution are known as members of the Scheduled Castes and Scheduled Tribes (also called Adivasi or original inhabitants). According to the 2011 census, there are in the order of more than a thousand scheduled castes across 29 states, and 744 scheduled tribes [6], although the popular press in India claims that half of the Dalit population are concentrated in four states [7]. Never-theless, this represents a significant portion of the pop-ulation who have experienced disadvantage: $16.2 \%$ of India's citizens are from a Scheduled Caste and $8.2 \%$ from a Scheduled Tribe [8]. Researchers such as Sachar (2006) also see that socio-religious diversity creates levels of social and economic disadvantage in India's population [9].

Areas of diversity such as language, religion, and caste can have a significant impact on education because it is these systems of formalized difference that account for who is included (privileged) and who is excluded for access to the rights of citizenship, and one of these rights is the right to an education. Accord-ing to Tilak (2000) there is a lack of equity of access to education in India, and poverty is inversely corre-lated with educational access, retention in school, and educational success [10]. Tilak argues also that the poverty and lack of educational attainment are mutually reinforcing. If a person does not have access to education then they lack the means to move them-selves out of poverty [10]. In addition to the other ar-eas of diversity already discussed, there are also large disparities in enrolment in higher education across dif-ferent regions of the country [10].

Another significant area of difference is disability, which is part of the human condition [11] and is, in itself, a complex term that defies definition. Gradually however, disability is coming to be seen less as a factor of a human's ability to function and much more as an interaction between individuals and their environments [11]. This means that disability is com-ing to be seen less as an attribute of the person, and more of a function of how society is able to meet the needs of each individual so that each person can par-ticipate fully in life. A significant portion of the global population experiences this disability interaction with their environment - likely in the range of $15 \%$ [11]. Rao who writes about the Indian context, sees this more as a shift from seeing the child as the problem to seeing the system as the problem. Her conceptualiza-tion of the shift needed for inclusive education is shown as Figure 1

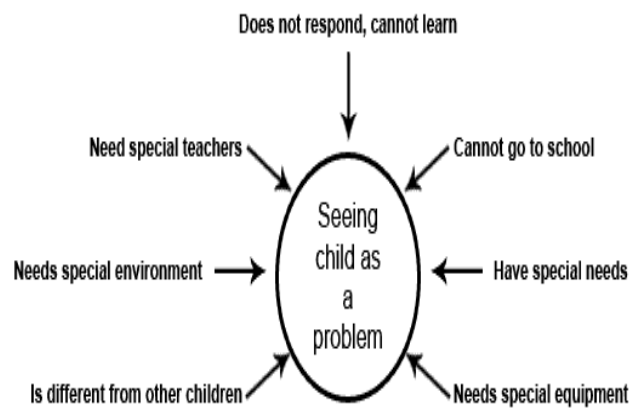

Integrated Education 


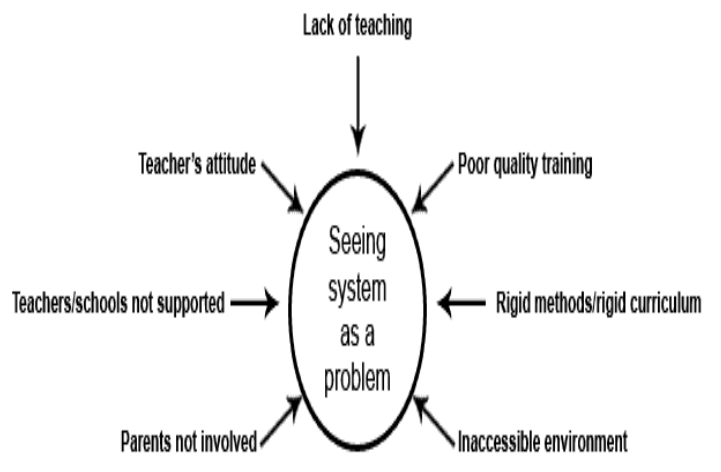

Figure 1. Integrated Education

According to Singal [13] the prevalence of disability in India is difficult to determine with estimates in the range of 18-22 million but this is likely an underreported figure. What is most significant however is how disability can keep children out of school. Children with a disability are reportedly five times more likely to be out of school than children from a scheduled tribe or caste [13].

In summary, India is a country which is rich in diversity through its many languages, geographic regions, diverse religious groups, income levels and ranges of its interactions with the human condition. In the next section, we examine more closely a continuum of educational approaches to diversity.

\section{3. “Approaches to difference” continuum}

Kalantzis and Cope [2] discuss contemporary learning with all of its challenges and theorize a continuum of approaches to difference at three levels: exclusion, assimilation, or inclusion. In a system of $e x-$ clusion, those who are different are not included in the school system, or they are perhaps in the school but not in the classroom with other students. Under a system of assimilation, those who have an area of difference are moved into the existing school community and they are expected to become like others already in the system. Everyone is immersed in the same curriculum and there are standards by which all students are either successful or not successful. The challenge with exclusion and assimilation approaches is the growing recognition that people are diverse by nature and by design. They have different experiences, backgrounds, social classes, cultures, races, and corporeal attributes. It has become less acceptable now to compare differ-ent body shapes and sizes, for example, and label them as deficit compared against a norm. The focus is shift-ing instead to how the environment can provide con-ditions for enablement so more people are included in the vision of the school. When viewed this way, it is the social institution that becomes the source of the disability, and the source of the disability does not reside with the person [2].

Kalantzis and Cope argue persuasively that demographic differences have become over-simplified as students have been classified and binaries such as able/disabled are too simplistic and counter-productive. What is needed, instead, is a more transformative view of education where individuals are able to participate and succeed while differences are not just acknowledged but expected. This creates a challenge for schools to create inclusive environments [2]. In other words, the answer lies not in further labelling and fragmentation but in creating the conditions where more students are able to succeed. Kalantzis and Cope refer to this as "a knowledge ecology of productive diversity” [2]. This approach aligns with UNESCO's policy guidelines on inclusion, "An inclusive education system can only be created if ordinary schools become more inclusive - in other words, if they become better at educating all children in their communities [14].

\section{Methodology}

We were invited to visit India in order to gain a first-hand understanding of schools in India who were working on inclusion. Our gracious hosts were the Adhyayan Foundation which is a leadership initiative for quality schools which has now reached close to 300 schools, and more than 300,000 students across 27 states and 9 languages in India [15]. Adhyayan and its members have created and refined a selfreview process for schools using quality standards that have been agreed upon as "what good schools look like" across a number of key performance areas [16]. The Adhyayan Foundation is working on a quality schools diagnostic framework for inclusion, and we were in-vited to collaborate on the diagnostic tool. They ar-ranged for five school visits. During the visits, we ob-served and made notes independently on what we ob-served in the schools. Later, we compared notes and compiled them into a single data set of the school vis-its. In order to make sense of the data, we read it through and used a process of open coding to identify an initial list of categories and concepts that were pre-sent in the data [17]. Using this open coding, key themes were identified in the observations. These are reported here after snapshots of the schools in the next section.

\section{Snapshots of Inclusive Schools}

The Canadian team was most fortunate to gain access to five schools that were working on inclusion through their connection with the Adhayan Foundation. Each of the schools is described next, highlight- 
ing how different schools with a commitment to inclusion are providing unique, student-centered solutions to inclusion challenges within caring communities.

\subsection{The Gateway School of Mumbai}

The first school visited was the Gateway School of Mumbai. The school was founded by a parent who was seeking a school for her child that matched his learning needs. It is inspired by the educational philosophy of educators at a school in the US. The teachers are employing explicit models of instruc-tion toward the goal of independence. Instructions and models are provided but students gradually assume more responsibility for their own learning. The stu-dents are ages 5-18 years old and all have special needs; the classes are set up so that students within the class have complementary learning profiles, based on their needs. The classroom model is purposefully de-signed to teach both language and behaviour in an ac-tive learning or problem-solving/inquiry type of peda-gogy. In one of the classes we visited, a student asked, "How big is Google?” and this is the type of student-initiated question that opens up inquiry learning for students. The program is fully inclusive and English is the language of instruction.

In the debrief following the classroom visits, the discussion focused on how many different teaching styles are needed to accommodate so many different students' learning needs. The teaching staff at Gateway talked about the difficulty for their students to transition back to mainstream schools because it has taken the teachers a significant amount of time to acquire this range of teaching strategies. The teachers told us that planning for so many diverse student needs is significant and good planning takes a long time, so they have built time into the school day for reflective planning for the educators.

\subsection{Shishuvan School, Mumbai}

The second school visit was to Shishuvan School in Mumbai where we observed classes that are focused on an active learning philosophy that is stu-dent-centered. Throughout the school, students were working on projects that they had initiated, and were investigating and presenting to their peers. It was ex-citing to see.

Shishuvan is pioneering an integrated program for first-generation learners who have not had previous exposure to English. In the first year of the program, they had students in Grades 5-8. The goal of the integrated program is to define success by how well the students do in life and in their vocation. At the present time there is one group of students who come from a lower socio-economic status, and these students (boys) are boarding at the school. They have a step-up program based on boys' interests that helps to bridge the experience gap between students who have had regular access to events in society (such as films) and those who have not. The step up program is also assisting the students with social integration.

While the school is working hard to make the integrated setting work, they acknowledge that some of the biases present in the larger society can also make themselves felt within the school setting. The teachers of the integrated class volunteer for that role and build personal connections with the students. One of the strategies that they are using is working from the point of view of the student's experience starting with the student. This was a familiar theme in all of the Mother Tree schools. During our tour of this school, we were treated to multiple samples of Grade five boys' hu-mour which, we discovered, appears to be universally amusing.

\subsection{HLC International, Chennai}

The third school visit was to the HLC Interna-tional School in Chennai. On their webpage they de-scribe the school as a social incubation center. Here the philosophy established is student-centered learning using co-teaching. The teachers are often subject-specialists but they teach in the mainstream classrooms. They do not see themselves as "special educators" rather as facilitators who practice a philosophy of sup-porting the student's wellbeing and development. This school has also worked to individualize the curriculum to meet each student as an individual learner. To plan for learning, the teachers look at the school vision and the traits of the students before they consider the learn-ing objectives and plan the lesson with differentiation. This is a significant shift from starting with the learn-ing outcomes and then trying to meet the student needs. HCL provides a fully inclusive environment for every student including those with mild to severe spe-cial needs. This school is also pioneering a functional curriculum based on best practices globally and cus-tomized to the needs of their learners.

Inclusion is part of the fabric of the school as much as the walls and stairs. For example, the occupa-tional therapy (OT) room is open to every child, not just those who have OT needs. The HLC School works closely with parents, with a goal of having every par-ent spend a half-day at the school over the next two years. The parents are engaged in various activities ranging from career counselling sessions, to new tech-nology workshops and organizing fund raising carni-vals.

HLC has a new school building design that is circular, and students have decorated the walls with their art. We observed that the school is quietly but 
persistently inclusive and integrated. We noted students from a wide range of backgrounds and needs, and they were supported by staff who treated each with respect and dignity.

Classes are working on student-led social jus-tice projects in their communities. The teachers are working on an outreach program to make education available to students who have not yet attended school. One of the highlights of the school visit was a trip to the horticultural outdoor classroom where students were busy planting, harvesting and working in the gar-den to produce crops. The model of integration also allows for a small portion of the day not spent in the integrated setting. What is compelling in the discus-sions with the teachers are their reflections on their own learning and growth with respect to meeting the needs of every child. There was an atmosphere in this building of trust, respect, and an openness to new learning and pedagogy. One of the teachers explained to us that inclusion at their school is not a program - rather it is belonging.

\subsection{Bombay International, Mumbai}

The fourth school we visited was Bombay International School where the students were engaged in exams, so we had an opportunity for an extended visit with the teachers and school staff. In this school, they define integration as what makes the child happy. The teachers describe that, some years ago, they decided that they wanted to be actively in the space of inclusive learning. They wanted to embrace new approaches and shift from being reactive to proactive.

Their classes are bilingual with English, Hindi or Marathi. The teachers have struggled with students who are integrated in classes but have very different experiences and backgrounds because of their position on the income strata. They are employing multiple strategies to address this. One of the strategies that they are employing is to avoid pulling students out of class. For this reason the school employs psycholo-gists who are in the classrooms and the students feel supported and connected. Another strategy they use is to allow the students to visit the psychologists with a buddy so that they normalize the process of counsel-ling and reflecting.

The staff told us some great stories of integra-tion. In one instance, all of the students in the class wore an eye patch so that they "matched" the student who needed the patch. In another instance for a child who was not talking, the students included the child in the play as a lip-synching character.

The teachers are working to write a new curriculum based on non-academics, such as introspection. They want their students to have empathy, understand-ing and respect. Interestingly, they reported that more than 300 teachers applied to work at this school last year.

\subsection{The Heritage School, Gurgaon}

Our final stop was the Heritage School in Gur-gaon where we were able to speak at some length with the school principal and hear about inclusion from the perspective of a school leader. On the school website, the students explain that the focus of the school is on learning by doing. The school focuses on the holistic needs of individual children: mental, social, physical as well as intellectual. While the school started out as a private school, now everyone in the neighbourhood can attend the school and there is the expected mix of levels of English acquisition, learning needs and other areas of challenge. In other words, Heritage offers a fully inclusive school environment, working with each student individually.

One of their efforts at the present time is the creation of a school to work program, working with a global corporation (Lemon Tree) for hotel employment. The goal of the hotel chain is to employ $80 \%$ of workers with disabilities.

Within the school, the language of instruction is English and Hindi is also spoken. One of the goals of the school is to include children from every economic strata, but, similar to other schools, they do find that it is easier if students are fully included in classes from an early age. They have used a number of strategies to make inclusion work such as case conferences and offering support in the classroom. They helped us understand how schools need to be sensitive to social hierarchy because societal beliefs have an impact on how students see themselves and how others see them. Even within some social groups, there is a longstand-ing hierarchy that may eventually change with time and education.

At Heritage they took a moderated approach to student-centered learning, focusing on hands-on learn-ing and experiential learning which was more condu-cive to inclusion. Their words resonated with us, "We embrace inclusion and we expect you to embrace it too."

\section{Discussion: Mother tree schools}

As we analyzed our findings from the school visits, we began to construct a metaphor for the types of inclusion that we had seen in the schools that were selected for us to observe in India. In this analysis we were guided by the UNESCO statement on inclusion: how ordinary schools need to become better at educat-ing all of the children in their communities [14]. This resonated with the approach that we had seen working in the small sample of schools we visited. 
It occurred to us that the model schools we observed were operating much like the ecosystem in a forest. Dr. Suzanne Simard, a professor at the University of British Columbia in Canada theorizes that, rather than viewing trees and plants as organisms that compete with each other, instead we can view trees as communicating with each other in order to help each other survive. Her research shows that trees support each other in silent, unobtrusive ways through the exchange of nutrients facilitated by fungi in the ground who wrap themselves around the roots of the trees. The Mother Trees are the ancient and dominant trees in the forest and their roots are linked to all of the trees within a human gaze from the trunk of the Mother Tree through literally hundreds of miles of root systems. Many different species of trees are connected to the root system of the Mother Tree, and she supports and communicates with a wide range of diverse tree types. According to Simard, this biodiversity is intentional in the forest. All of the parts work together, and in the event of a disaster, some types of trees are likely to survive while others may not [18].

Similarly, Wohlleben's research indicates that trees are social beings who exist in community and communicate with each other. In undisturbed beech forests, trees did not compete, but synchronized their growth so that all of the trees were equally successful, even in different growing conditions. Trees appear to equalize the difference between strong and weak trees by shuffling nutrients underground and sharing light with each other as they mature [19].

These mother trees inform as a metaphor for inclusive schooling for multiple reasons. The mother trees are the ancient trees, valued for their longevity and experience. These are the founders, leaders and teachers within the inclusive schools. Within the schools we observed, there was a strong ethic of seeking knowledge from both new and experienced teachers and sharing this knowledge. Other trees congregate and grow near the mother trees, trusting them for com-munication, collaboration and exchange of nutrients. Mother trees seek out and identify the trees who are not functioning well or developing slowly and provide invisible support through a differentiated system of feeding them through the root system.

Every inclusive school we visited in India pro-vided indications that they were attempting to provide this ethos of care through unobtrusive ways. Mother trees provide more sustenance to under developing trees, directing nutrients to the trees that are the least likely to survive through a hidden, almost invisible network.

Within the ecosystem of the forest, biodiversity is not a problem: it is anticipated and expected. Diversity is seen as a strength that gives the forest resilience. Everything and everyone "belongs" in the ecosystem, and the system is characterized by co-operation rather than competition. Some trees move their shade or adapt their shade growth so that other trees can have sunlight [19]. The trees are part of a system - what happens to one aspect of the ecosystem affects other aspects, so they are engaged in mutual forms of support at different levels. For these many reasons, we saw the schools we visited in India as Mother Tree schools.

\subsection{Incubator schools: California}

In the introduction to this paper, we quote a California study [1] that focuses on the practices and policies of the highest-performing charter schools. The research started with 30 schools and narrowed it to 10 schools. The characteristics of the strongest schools are as follows:

1. A philosophy of inclusion. The students who had learning needs were generally in the regular classroom where they were exposed to rich content.

2. Individualized learning programs were provided for students rather than sending students out to special programs.

3. Differences were anticipated and seen positively in a supportive community.

4. There were multi-tiered support systems.

5. There were strong partnerships with families and communities.

6. The schools were using innovative and emergent technologies for students with needs.

7. The schools exercised both flexibility and autonomy in offering a range of programs.

8. A high priority was placed on recruitment and staff development.

9. There was a focus of continuous improvement and evaluation of the school's practices to meet student needs [1].

The observing Canadian team could not help but notice the strong similarities between the schools visited in India and the list of characteristics of high performing inclusive schools from the California Charter Schools Association [1]. The Mother Tree schools in India were practicing virtually all of the pol-icies and practices of inclusion identified in the Cali-fornia research. This also resonated with current On-tario policy (Ontario is the home province of the au-thors.) The Ontario education policy is called Learning for All [20]. This policy proposes that teachers in On-tario apply a combination of Universal Design for learning principles with methods of differentiating in-struction. Under this policy, teachers are asked to con-sider at least three ways to offer differentiated pro-gramming to every student, not just the students who have special needs. For example, teachers are ex-pected to: 
1. Differentiate the content for students;

2. Differentiate the process or how the material is taught for different students;

3. Differentiate the product that students produce; and

4. Differentiate the environment for students.

The intent of the policy is that, if the teachers are focusing on student-centered, differentiated learn-ing, they will be able to meet the needs of more students in the class without as many students having to be identified as a student with special needs. The schools we visited in India were already working toward student-centered and individualized types of pro-gramming. There was, however, one area identified in the California study where we saw some but not a great deal of evidence of change in the schools in India that we visited, and that was the area of technology. This is discussed in the final section of the paper.

\section{Conclusions}

The schools in India that we observed have yet to experience in full the digital revolution currently happening in some schools in other countries. This could be described as the use of assistive devices in the hands of the students (or at the point of learning) that can significantly change how children learn. As this revolution happens around the world, we predict that it will also happen in schools in India. Here we are not talking about identifying students and providing ex-pensive devices that take time for both the teacher and the student to learn how to use. We are talking about assistive technologies which are disguised (intention-ally) as every day communication devices [21]. These devices are going to change the dialogue globally away from the ability/disability binary, and open new windows to children who learn differently.

Emerging technologies enable all learners, including learners with special needs such as Google's Read and Write. Instant transcription is now available through apps such as the PowerPoint Translator which automatically transcribes the speaker's voice as slides are presented, and can also translate the transcription simultaneously during the slide presentation.

Technology is already beginning to democra-tize the design and use of assistive devices. A few examples show the way forward. Consider the example of Ben Ryan, a Welsh father, who designed a prosthetic arm for his son using a Kinect Box and a 3-D printer when physicians said that his son would have to be older to have a prosthetic [21]. Technology is placing devices that will make a difference in the hands of every day persons for just-in-time individu-alized solutions.
A second example is the Be My Eyes solution to assist persons all over the world who have difficulty with vision [23]. Be My Eyes is an iPhone app that relies on volunteers. Presently more than 30,000 persons who are blind have registered with close to half a million sighted volunteers. The app on the phone allows a person with weak eyesight to call a volunteer at any time of day or night to ask them to read something to them such as instructions or a prescription label. Once again, an easy solution through every day tech-nology.

As technology offers more affordances such as voice-to-text recognition software that works with different accents and dialects, and text-to-voice applications, as well as translation applications, the growth and democratization of technology we predict will provide a powerful high-leverage mechanism for mak-ing learning inside and outside of school more acces-sible to all learners.

It was our privilege to visit and observe in the Mother Tree schools in India, model schools with inclusive philosophies and student-centered, active learning strategies in place. Furthermore, the leadership that these Mother Tree schools provide extends beyond their immediate school district and community. Technology has allowed us to develop a network of educators nationally and globally to discuss inclusion. With cross-platform instant messaging applications, such as WhatsApp, educators engage in discussions regularly on the topic of inclusive education, cur-rent pedagogy, and best teaching and learning prac-tices. The sharing of knowledge, research, practices in the classroom and new ideas has enabled educators from what we have called Mother Tree schools to sup-port a broader network of schools, irrespective of geo-graphical proximity.

The resulting discussions within the group demonstrate the eagerness of teachers to build a nurturing environment that makes education accessible to more students. It also is a space where active reflec-tion and informal professional development occur as teachers share their practices and concerns and subse-quently receive feedback that enables them to develop professionally. The sharing of knowledge and prac-tices between educators in various states in India and other countries allows the understanding and imple-mentation of inclusive practices to move closer to be-coming a reality for more students.

The opportunity to observe Mother Tree schools has allowed more introspection of our own practices and further added to our knowledge and understanding. It has enabled us to critically analyze the successes and gaps that currently exist as we forge for-ward in a global movement to provide accessible and high-quality education for all learners. 


\section{References}

[1] California Charter Schools Association (2016).Meeting the needs of every student through inclusion. Retrieved @ www.ccsa.org/2016-Special-Education-Report.pdf.

[2] Kalantzis and Cope (2012) Kalantzis, M., and Cope, B. (2012). New learning: Elements of a science of education. Cambridge University Press.

[3] World Bank (2020). The World Bank in India. Retrieved @, http://www.worldbank.org/en/country/india.

[4] Dasgupta, J. (1970). Language conflict and national development: Group politics and national language policy in India (No. 5). Univ of California Press.

[5] Masani, Z. (2012) English or Hinglish: Which will India Choose? Retrieved @ http://www.bbc.com/news/ magazine-20500312.

[6] Census of India 2011, Primary Census Abstract Scheduled castes and scheduled tribes, Office of the Registrar General and Census Commissioner, Government of India (October 28, 2013).

[7] Sivakumari, B. (2013). Half of India's dalit population lives in 4 states. Times of India. Retrieved @ http://timesofindia.indiatimes.com/india/Half-of-Indias-dalit-popula-tionlives-in-4-states/articleshow/19827757.cms

[8] Office of the Registrar General and Census Commissioner, India, 200. Found @ http://censusindia.gov.in/Census_And_You/scheduled_castes_and_sceduled_tribes.aspx.

[9] Sachar, Rajindar (2006). "Sachar Committee Report (2004-2005)" (PDF). Government of India. Retrieved @ http://www.teindia.nic.in/Files/Reports/CCR/Sachar\%20Co mmittee\%20Report.pdf.

[10] Tilak, J. B. (2000). Education poverty in India. Na-tional Institute of Educational Planning and Administration. $\quad$ Retrieved 9/8/2017 @http://www.nuepa.org/New/down-load/Publications/ NUEPA\%20Occasional\%20Pa-per\%20No-29-EDUCATION\%20PROVERTY\%20IN\%20IN-DIA_JANDHYALA \%20B\%20G\%20TILAK_D-10742.pdf.

[11] World Health Organization WHO, W. (2011). World report on disability. Geneva: WHO. Retrieved @ http:// www.who.int/disabilities/world_report/2011/re-port.pdf? ua $=1$.

[12] Rao, I. Rao, I. (2003). Inclusive Education in the Indian Context. In meeting on inclusive education organized by NCERT (pp. 16-17). Retrieved 9/8/2017@ @www.addc.org.au/.../inclusive-education-inthe-indian-con-text_966.docx.
[13] Singal, N. (2009). Education of children with disabilities in India. Background paper prepared for the education for all global monitoring report 2010. Paris: UNESCO. Retrieved@https://unesdoc.unesco.org/ark:/48223/pf00001866 11.

[14] UNESCO (2009) Policy Guidelines on Inclusion in Education. Retrieved 9/8/2017@ @ http://www.inclusive-education-in-action.org/iea/dokumente/up-load/72074_177849e. pdf.

[15] Robertson, L., Srikantha, J., Harvey, J., and Anand, K., and Thomas, D. (2016). Examining New Vistas in Leadership Learning with Technology. Higher Education in Transformation Symposium, Oshawa, Ontario, Canada, November 2-6. Retrieved@ https://arrow.tudublin.ie/cgi/viewcontent.cgi? article $=1002 \&$ context $=$ heit 166 .

[16] Hillman, S. L., Anand, K, and Gupta, S. (2015). Assessing quality of education in Indian schools on six key performance areas. Literacy Information and Computer Education Journal (LICEJ), 4(1), 2146-2154. Retrieved from: http://infonomics-society.ie/wp-content/up-loads/licej/ published-papers/special-issue-volume-4-2015/AssessingQuality-of-Education-in-Indian-Schools-on-Six-KeyPerformance-Areas.pdf.

[17] Lichtman, M. (2012). Qualitative research in education: A User's Guide: A user's guide. Sage.

[18] McKinney, D. (2011) Mother Tree. Youtube accessed 9/8/2017@https://www.youtube.com/watch?

$\mathrm{v}=-8 \mathrm{SORM} 4 \mathrm{dYG} 8$.

[19] Wohlleben, P. (2016). The Hidden Life of Trees: What They Feel, How They Communicate Discoveries from a Secret World. Greystone Books.

[20]. Ministry of Education, Ontario (2013). Learning for All. A guide to effective assessment and instruction for all students, K-12. Retrieved 9/8/2017@ @ttp://

www.edu.gov.on.ca/eng/general/elemsec/speced/LearningforAll2013.pdf.

[21] Robertson, L., White, H., Clarkson, J. and Ellis, H. (2014). The Teacher's Role in Assistive Technology for Everyday Inclusion. Refereed paper. ICET 58th World Assembly, July, 2014. pp. 295-307. Retrieved 9/8/2017 @ https://shared.uoit.ca/shared/department/.../ICET-58thWorld-Assembly-Proceedings.pdf.

[22] Herd, G. March 1, 2017. Meet the father printing his son's arm. www.bbc.com/news/uk-wales-39106937.

[23] Be My Eyes. Retrieved 9/8/2017@ bemyeyes.com. 